\title{
Level of anxiety versus self-care in the preoperative and postoperative periods of total laryngectomy patients ${ }^{1}$
}

\author{
Clara Inés Flórez Almonacid² \\ Alfredo Jurado Ramos ${ }^{3}$ \\ María-Aurora Rodríguez-Borrego ${ }^{4}$
}

\begin{abstract}
Objective: estimate the prevalence of anxiety in laryngectomy patients in the pre and postoperative periods and its relation with the self-care level. Method: observational research of 40 patients with stage IV laryngeal cancer. Three observations took place: in the preoperative phase, at seven and at 14 days after the surgery; between June 2010 and December 2012. Two self-care levels were defined: self-sufficient and needing help for activities of daily living and treatmentrelated activities. To assess the anxiety levels, Zigmond's hospital anxiety scale (1983) was used. Results: in the preoperative and postoperative phases, the patients presented high levels of anxiety. Concerning self-care, on average, self-sufficient patients presented lower levels of anxiety than patients who needed help to accomplish activities of daily living and activities deriving from the surgery, without significant differences. Conclusion: anxiety is present at all times in laryngectomy patients and the reduction of the self-care deficit seems to decrease it, without putting a permanent end to it.
\end{abstract}

Descriptors: Neoplasms; Laryngeal Mucosa; Laryngectomy; Anxiety; Adjustment Disorders; Activities of Daily Living.

\footnotetext{
${ }^{1}$ Paper extrated from Doctoral Dissertation "Nivel de ansiedad versus nivel de autocuidados en el paciente laringectomizado", presented to Universidad de Córdoba, Córdoba, Andalucía, Spain.

2 PhD, Associate Professor, Departamento de Enfermería, Universidad de Córdoba, Córdoba, Andalucía, Spain.

${ }^{3}$ PhD, Full Professor, Departamento de Medicina, Universidad de Córdoba, Córdoba, Andalucía, Spain.

${ }^{4}$ PhD, Full Professor, Departamento de Enfermería, Universidad de Córdoba, Córdoba, Andalucía, Spain.
}

Flórez-Almonacid CI, Jurado-Ramos A, Rodriguez-Borrego MA. Level of anxiety versus self-care in the preoperative and postoperative periods of total laryngectomy patients. Rev. Latino-Am. Enfermagem. 2016;24:e2707. [Access if 1 ]; Available in: month day year DOI: http://dx.doi.org/10.1590/1518-8345.0743.2707 


\section{Introduction}

Laryngeal cancer is emotionally traumatic, due to the change in the body image and functional deterioration resulting from the cancer and its surgical treatment; considering that the patients fear a bad prognosis, the pain, the loss of dignity, physical disfigurement and worsening of communication; the loss of this function can provoke feelings of vulnerability, sadness and fear ${ }^{(1)}$.

Anxiety, in turn, is an emotional response or response pattern that comprises cognitive aspects: unpleasant, tension and apprehension; physiological aspects characterized by a high degree of activation of the autonomous nervous system (ANS) and motor aspects, which tend to imply maladjusted and hardly adaptive behaviors(2). The North American Nursing Diagnosis Association (NANDA) established a diagnostic label called Anxiety, defined as: "A vague, uneasy feeling of discomfort or dread accompanied by an autonomic response, with the source often nonspecific or unknown to the individual; a feeling of apprehension caused by anticipation of danger. It is an altering signal that warns of impending danger and enables the individual to take measures to deal with threat"(3).

Psychological morbidity is frequently underdiagnosed. While most patients are capable of facing their anguish and adapting to changes, some experience more anguish, anxiety and depression ${ }^{(1)}$. The prevalence of anxiety in head and neck cancer patients greatly varies; several authors have estimated that the prevalence of anxiety ranges between $5 \%$ and $87 \%{ }^{(4-6)}$.

Despite considerable advances in the surgical techniques designed to minimize the dysfunctional image and changed imaged in the postoperative phase, the results are traumatic for the patient ${ }^{(7-8)}$.

Some authors ${ }^{(1,9)}$ have demonstrated that the recovery after a head and neck cancer surgery can include long-term physical, emotional, social and behavioral debilitating sequelae, and that the anxiety can continue increasing linearly after the end of the treatment.

Another aspect that stands out in total laryngectomy patients is that specific care is required, deriving from the surgery, which the patient needs to learn with a view to daily self-care. Laryngectomized patients experience different modifications, causing self-care needs and a self-care deficit, which should be solved or compensated to prevent complications, live with their disease and develop appropriately, incorporating self-care into their daily life as a fundamental tool to contribute to the maintenance of their health and improvement of their quality of life $\mathrm{e}^{(10-11)}$.
The analysis of the information described reveals a lack of research on the psychological consequences and self-care of laryngeal cancer patients during the preoperative and immediate postoperative phases. Although different studies have examined the psychosocial aspects of cancer, the death threat, body image problems, fears of treatment (surgery, radiation and chemotherapy), the family's reaction to the potential image change, social and professional problems, and psychological reactions like the laryngeal cancer patients' anxiety and depression during the chemotherapy/radiotherapy or during the rehabilitation, research in the immediate periods before and after the surgical treatment is scarce. Therefore, this study was undertaken in response to the question about whether patients with higher anxiety levels have a greater selfcare deficit; and aiming to estimate the prevalence of preoperative and immediate postoperative anxiety in laryngectomized patients and its relation with the selfcare level.

The reference framework in the care for these patients was: Orem's general theory, which consists of the Self-Care Theory (SCT), Self-Care Deficit Theory (SCDT) and Nursing System Theory (NST) ${ }^{(12-13)}$.

The development of Orem's Self-Care Theory is ordered and systematic, offering a global assessment of the patient. In addition, it can be used in any cancer stage and defines the activity range of the nurse, the patient and the caregivers, with a view to satisfying the patient's Self-Care Demands ${ }^{(12)}$.

Self-Care (SC) is the set of actions a person performs to control internal or external factors, which can compromise that person's life and further development. Orem departed from the premise that all individuals are capable of satisfying their selfcare needs ${ }^{(12)}$. The Self-Care Deficit (SCD) explains the relation between the person's abilities and power to achieve the objectives of SC. The self-care deficit does not refer to a specific limitation, but establishes the relation between what the individual is capable of and his/her needs. When the SCD is established, professional nursing interventions are made for some time to compensate for it; Orem calls this Therapeutic Self-Care Demand (TSCD) ${ }^{(12-13)}$.

When a self-care deficit exists, the nurse is able to compensate for it through the Nursing System (NS), which can be: wholly compensatory, partly compensatory and supportive-educative ${ }^{(12)}$.

\section{Method}

Observational study of patients medically and surgically judged with total laryngectomy, with a final 
diagnosis of squamous cell epidermoid carcinoma (stage T4), during their hospital stay at the Clinical Otorhinolaryngology Service of a tertiary hospital in Southern Spain, between June 2010 and December 2012. The sample size was calculated to estimate a proportion in finite populations (based on the number of total laryngectomy patients in 2008-2009 hospitalized at the research hospital, corresponding to an average 45 persons). With a prevalence of $3.4 \%$ of laryngeal cancer in Spain, a $2 \%$ precision level and a $95 \%$ confidence level, the sample size was 40 cases. Sampling happened consecutively to the patient's internment for intervention at the research hospital.

The research variables were: preoperative anxiety $\left[t_{0}\right]$, at seven $\left[t_{1}\right]$ and $14\left[t_{2}\right]$ days after the surgery, demographic data [gender, age, hospital stay], smoking habit [smoker, former smoker (having quit smoking one year before the start of the study) and non-smoker], alcohol consumption [drinker, former drinker (having quit drinking one year before the start of the study) and non-drinker], self-care level [self-sufficient, needs help with care activities: self-care deficit (yes-no) and support networks [yes-no].

To measure the anxiety, Zigmond's Hospital Anxiety and Depression Scale - $\operatorname{HADS}^{(14)}$ was used, developed to detect anxiety (anxiety subscale HADS-A) and depressive disorders at non-psychiatric hospital services, avoiding overlapping with symptoms caused by physical illness. This self-reported scale consists of 14 items, seven of which measure anxiety. The response format is a four-point Likert scale. One of the advantages is its short response time. In the scoring of the anxiety subscale, scores between 0 and 7 points are not considered as cases, scores between 8 and 10 as doubtful cases and between 11 and 21 as cases. The anxiety subscale (HADS-A) contains seven items, scored between 0 (never, normal) and 3 (continuous, very intense), considering scores of 11 or higher as "defined cases". Nevertheless, various studies use different cut-off points, referring that a lower cut-off point provides excellent properties to detect psychological problems ${ }^{(15)}$. In this study, it was considered that, at cut-off point superior to 8 , the patients suffered from anxiety ${ }^{(15)}$. The anxiety subscale (HADS-A) was validated in the Spanish population, with a sensitivity ratio of $78 \%$ and a specificity ratio of $74 \%{ }^{(16)}$.

To value the support networks, the following were considered: whether the patient had a person for everything needed, occasionally, only for concrete things or no social networks.

For the self-care measure, Orem's theory was used. Two self-care levels were defined: self-sufficient and need help to accomplish activities (self-care deficits), operationally defined as the performance of activities of daily living (ADLs), assessed using Barthel's index (17), a questionnaire that measures the patient's ability for independent self-care, with a high reliability coefficient (Cronbachs alpha $0.86-0.92$ ). Its replicability is excellent, with weighted kappa correlation coefficients of 0.98 intra-observers and over 0.88 inter-observers, and international consistency (Cronbach's alpha 0.86$0.92)^{(18)}$. The Barthel index assesses ten activities of daily living: feeding, bathing, dressing, grooming, toileting, bowel control, bladder control, chair transfer, ambulation and chair climbing. The total score ranges between 0 and 100. Dependence is mild when the score ranges between 91 and 99, moderate between 61 and 90, severe between 21 and 60 and total for scores inferior to $20^{(17)}$. In this study, the patients were classified according to the score, as follows: selfsufficient if Barthel index 90-100; need help if Barthel index 21-90 and dependence if Barthel index inferior to 21 .

The self-care activities specifically related to the surgical procedure were grouped as independent or in need of help to perform them; the activities were assessed using the nursing outcomes classification, based on the outcome: acceptance of health condition, and the indicator: performs care deriving from the surgery: mobilization of tracheobronchial secretions (effective cough), stoma care (cure, change of tracheotomy cannula), sleep in half-seated position, communicate in writing and nasogastric tube feeding. Patients were classified as independent and in need of help to perform the activities ${ }^{(19)}$.

On the day the patient was hospitalized for the surgical intervention, defined in the study as the presurgery $\left(t_{0}\right)$, the patient was interviewed to provide a detailed explanation on the purpose of the study and to request informed consent in writing; if the patient agreed, sociodemographic data, affiliation, disease and toxic antecedents were collected. The patient, in turn, completed the self-reported anxiety scale (HADS-A) and the self-reported self-care level for activities of daily living and surgery-related activities.

At seven $\left(t_{1}\right)$ and $14\left(t_{2}\right)$ days post-surgery, the patient was again interviewed to revise the clinical history, assess the self-care level (self-sufficiency or help with activities of daily living and surgery related activities), the presence of family networks was reassessed and the patient completed the selfreporting.

The research protocol received approval from the research ethics committee of the hospital center. The study was undertaken in accordance with the 
requirements formulated in the Helsinki Declaration (Seoul revision, October 2008) and Spanish law regarding the treatment, information and transfer of personal data of all participants, in compliance with the determinations in Organic Law 15/1999, dated December $13^{\text {th }}$, on the Protection of Personal Data and RD 1720/2007.

In the statistical analysis, the patient's characteristics are described through frequencies and percentages for qualitative variables, or averages, standard deviations (SD), minima and maxima for quantitative variables.

For the variables anxiety and self-care level, repeatedly measured in the same patients (preoperative, at seven and 14 days postoperative), the description and statistical analysis techniques used were techniques for repeated data. The quantitative variables are described as differences of means among the different times in the study (among $t_{0}-t_{1}-t_{2}$ ), SD for the differences and 95\% confidence intervals. The qualitative variables are described using frequencies and the change in the status of the category among the distinct study times. The bivariate relations between the qualitative variables of interest and the anxiety and self-care level variables were studied using contingency tables at each clinical time, as well as the chi-squared test or Fisher's exact test (in case the percentage of crosses with expected frequency inferior to five was higher than 20\%). In addition, to study the variation or relation of the variables between the pre-surgery time and seven and 14 days postsurgery, the Generalized Estimation Equation (GEE) model was used.

\section{Results}

Among the 40 total laryngectomy patients studied, 38 (95\%) were men. The mean age of all patients was 61.73 (SD 11.08) years, with a maximum age of 82 and a minimum age of 42 years; in men, the mean age was 61.8 years (SD 11.2) and, in women, the mean age was 59.0 (SD 8.48). The mean length of the hospital stay was 18.5 (SD 4.8) days, with a minimum age of 14 and a maximum age of $38 ; 100 \%$ of the patients indicated they had been informed about the surgery and its consequences.

In Table 1, the socioeconomic and clinical characteristics and antecedents of the patients in the preoperative period are displayed.
Table 1 - Sociodemographic description and antecedents in the preoperative period of laryngectomy $(n=40)$. Cordoba, CAA, Spain, 2014

\begin{tabular}{|c|c|c|c|}
\hline Variables & Category & $\mathbf{N}$ & $\%$ \\
\hline \multirow[t]{2}{*}{ Gender } & Man & 38.0 & 95 \\
\hline & Woman & 2.0 & 5 \\
\hline \multirow[t]{4}{*}{ Education } & Primary & 28.0 & 70 \\
\hline & Secondary & 7.0 & 17.5 \\
\hline & College & 1.0 & 2.5 \\
\hline & Others & 4.0 & 10 \\
\hline \multirow[t]{3}{*}{ Marital Status } & With partner* & 29.0 & 72.5 \\
\hline & Separated & 8.0 & 20 \\
\hline & Single & 3 & 7.5 \\
\hline \multirow[t]{4}{*}{ Professional Situation } & Works & 17 & 42.5 \\
\hline & No job & 1 & 2.5 \\
\hline & Invalidity & 3 & 7.5 \\
\hline & Retired & 19 & 47.5 \\
\hline \multirow[t]{2}{*}{ Anxiety } & No & 12 & 30.0 \\
\hline & Yes & 28 & 70.0 \\
\hline \multirow[t]{3}{*}{ Tobacco Consumption } & Non-smoker & 1 & 2.5 \\
\hline & Smoker & 26 & 65 \\
\hline & $\begin{array}{l}\text { Former } \\
\text { smoker }\end{array}$ & 13 & 32.5 \\
\hline \multirow{3}{*}{ Alcohol consumption } & Drinker & 25 & 62.6 \\
\hline & Non-drinker & 10 & 25 \\
\hline & $\begin{array}{l}\text { Former } \\
\text { drinker }\end{array}$ & 5 & 12.5 \\
\hline \multirow[t]{2}{*}{ Support network } & Yes & 38 & 95 \\
\hline & No & 2 & 5 \\
\hline \multirow[t]{2}{*}{ Self-care level } & Self-sufficient & 34 & 85 \\
\hline & Help $\mathrm{ADL}^{+}$ & 6 & 15 \\
\hline
\end{tabular}

*With partner (married, consensual union). ${ }^{+}$ADL (Help for activities of daily living)

Initially, the patients presented a mean score of 9.325 (SD 3.392) on the subscale of hospital anxiety (HADS-A), with a minimum of 4 and a maximum of 18 . The patients entered the hospital feeling anxious and the anxiety level increased at seven days post-surgery, dropping almost to the baseline levels at 14 days postsurgery (Table 2 ).

Table 2 - Frequency and Percentage of patients with anxiety $(n=40)$. Córdoba, CAA, Spain, 2014

\begin{tabular}{lcc}
\hline & Anxiety & $\mathbf{P}$ \\
\hline Preoperative $\left(\mathrm{t}_{0}\right)$ & $28(70 \%)$ & \\
Postoperative 7 days $\left(\mathrm{t}_{1}\right)$ & $39(97.5 \%)$ & $\mathrm{p}=0.001$ \\
Postoperative 14 days $\left(\mathrm{t}_{2}\right)$ & $29(72.5 \%)$ & $\mathrm{p}=0.001$ \\
\hline
\end{tabular}

On average, anxiety increased 2.175 points between the preoperative period and at seven days after the surgery. Between days seven and 14, anxiety dropped by an average 1.925. Overall, in the interval $\left[t_{0}, t_{2}\right]$, anxiety increased by 0.25 . Anxiety levels were higher between the preoperative phase and seven days 
post-surgery than between the seventh and $14^{\text {th }}$ day post-surgery (Table 3 ).

Table 3 - Difference in anxiety between preoperative phase and at seven and 14 days after laryngectomy surgery $(n=40)$. Cordoba, CAA, Spain, 2014

\begin{tabular}{|c|c|c|c|c|}
\hline & \multirow{2}{*}{ Mean } & \multirow{2}{*}{ SD } & \multicolumn{2}{|c|}{$\begin{array}{c}\text { Confidence interval } \\
95 \%\end{array}$} \\
\hline & & & Inferior & superior \\
\hline $\begin{array}{l}\text { Differences between } t_{0} \\
\text { and } t_{1}\left(t_{0}-t_{1}\right)\end{array}$ & -2.17 & 2.65 & -3.02 & -1.32 \\
\hline $\begin{array}{l}\text { Differences between } t_{1} \\
\text { and } t_{2}\left(t_{1}-t_{2}\right)\end{array}$ & 1.92 & 2.16 & 1.23 & 2.61 \\
\hline $\begin{array}{l}\text { Differences between } \mathrm{t}_{0} \\
\text { and } \mathrm{t}_{2}\left(\mathrm{t}_{0}-\mathrm{t}_{2}\right)\end{array}$ & -0.25 & 3.44 & -1.35 & 1.35 \\
\hline
\end{tabular}

The variable anxiety was not statistically related with gender, age, professional situation, tobacco consumption, alcohol, functional level and presence of family network. Concerning the self-care level, when they were hospitalized, $85 \%$ of the patients were selfsufficient for activities of daily living. Seven days after the surgery, however, $97.5 \%$ needed help with meals, mobilization of secretions, care for the wound and laryngectomy cannula, communication, mobilization and activity. At 14 days post-surgery, 70\% still needed help to change the cannula (Table 4).

Table 4 - Frequency and percentage of patients' functional level in the pre- and postoperative period of laryngectomy. $(n=40)$, Cordoba, CAA. Spain 2014

\begin{tabular}{lcccc}
\hline & \multirow{2}{*}{ Preoperative } & \multicolumn{2}{c}{ Postoperative } & \multirow{2}{*}{ P } \\
\cline { 3 - 4 } & & 7 Days & 14 Days & \\
\hline Self-sufficient & $34(85 \%)$ & $1(2.5 \%)$ & $12(30 \%)$ & $<0.0001^{*}$ \\
Needs help & $6(15 \%)$ & $(97.5 \%)$ & $8(70 \%)$ & $<0.0001^{+}$ \\
\hline $\begin{array}{l}\text { Statistical significance between }\left[\mathrm{t}_{0}-\mathrm{t}_{1}\right] \\
* \mathrm{p}<0.0001 \text { between }\left[\mathrm{t}_{1}-\mathrm{t}_{2}\right]\end{array}$ & & & \\
$+\mathrm{p}<0.0001$ & & &
\end{tabular}

In the preoperative phase, $71.4 \%(n=25)$ of the patients were self-sufficient for activities of daily living (ADL) and presented anxiety. At seven days postsurgery, $97.2 \%(n=35)$ needed help for self-care such as hygiene, mobilization of tracheobronchial secretions (airway aspiration), change of tracheotomy cannula, written communication and nasogastric tube feeding and still presented anxiety; similarly, at 14 days postsurgery, $68.9 \%(n=21)$ needed help with tracheotomy care and still experienced anxiety, although less than after seven days. On average, self-sufficient patients presented lower anxiety levels than patients who needed help to accomplish activities of daily living and surgeryrelated activities, without significant differences (Figure 1).

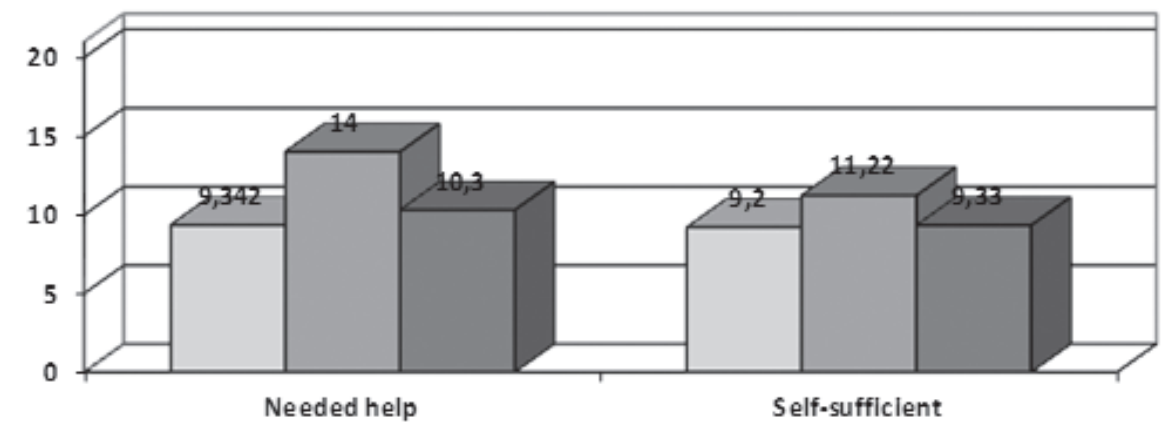

$\square$ preoperative $\square 7$ days postope rative $\square 14$ days postoperative

Figure 1 - Self-care and anxiety in preoperative and postoperative periods of laryngectomy $(n=40)$. Cordoba, CAA, Spain, 2014

\section{Discussion}

These study results should be taken with caution, as the sample size limits the weight of the findings; on the other hand, the scarce research on anxiety levels in the immediate postoperative phase of total laryngectomy support their publication.

Some studies $^{(7-9)}$ have demonstrated that the prevalence of anxiety in cancer patients in general is high.
Nevertheless, there are great prevalence differences, with figures ranging from $5 \%$ to $87 \%$; this range can be due to methodological differences, such as the use of different tools, different cut-off points, cancer staging, different types of cancer diagnoses or the phase in which the assessment took place. Although apparently contradictory, some studies, including meta-analyses, have demonstrated that, 
in comparison with a general population, the prevalence of anxiety in cancer patients is lower(5-6).

This study has evidenced that, in the preoperative period, patients' anxiety level is high and neither drops nor rises distinctly in the postoperative period. The high prevalence of preoperative anxiety found was similar to recent studies ${ }^{(8,20)}$. Nevertheless, in other studies, the prevalence is low, without surpassing 50\%(21-22).

Concerning the presence of postoperative anxiety, there is a lack of studies, generally involving radiotherapy patients; in most studies, fixed-term measures were used that do not consider the variation of time and its effects.

In this study, the increased anxiety was not statistically related with any of the variables studied. Nevertheless, it is clinically relevant that patients who presented preoperative anxiety, probably conditioned by the diagnosis, displayed even higher anxiety levels at seven days postoperative, with a reduction in self-care activities; at 14 days postoperative, on the other hand, anxiety levels had dropped and self-care activities had increased. This seems to be in accordance with authors ${ }^{(10-11)}$ who indicate that anxiety decreased in surgical patients with head and neck cancer at a specific point in time (fifth day postoperative). The increase in personal care, then, precedes the drop in anxiety levels. Self-care and anxiety have been significantly correlated on the fourth and fifth days after the surgery, with a relation between anxiety and self-care; a higher level of self-care corresponds to a lower level of anxiety.

During the first postoperative week, most patients need help for ADLs, have no voice, experience communication problems, with the presence of the laryngectomy cannula and abundant secretions, neck edema, drainage, parenteral fluids and appearance of mucus plugs that obstruct the cannula, causing a feeling of lack of air. At 14 days, however, the levels of anxiety and help for ADLs dropped, the patients had returned to their daily self-care and had gained abilities for most surgery-related self-care, except care for the laryngectomy cannula, for which six out of ten patients needed help.

This study reveals that the laryngeal cancer diagnosis causes anxiety. Nevertheless, it seems that self-care contributes to reduce anxiety levels. The high prevalence of anxiety found in the preoperative and postoperative phases in laryngectomized patients suggests that, in care for this kind of patients, a multiprofessional approach is needed to appropriately attend to the complex psychological needs of these patients and their families.

\section{Conclusion}

These study results on the prevalence of anxiety in the preoperative and immediate postoperative periods in laryngectomized patients and its relation with selfcare levels indicate that anxiety is present at all times in total laryngectomy patients.

\section{Acknowledgements}

To the patients, families, physicians and nursing team at the clinical otorhinolaryngology service.

\section{References}

1. Moore KA, Ford PJ, Farah CS. "I have quality of life... but...": Exploring support needs important to quality of life in head and neck cancer. Eur J Oncol Nurs. 2014 Apr;18(2):192-200.

2. Torrents R, Ricart M, Ferreiro M, López A, Renedo L, Lleixà $M$, et al. Ansiedad en los cuidados. Una mirada desde el modelo de Mishel. Index Enferm. 2013;22(1-2):60-4.

3. NANDA International. Diagnósticos enfermeros. Definiciones y clasificación 2009-2011. Barcelona: Elsevier; 2010. p. 235-6.

4. Haisfield-Wolfe ME, McGuire DB, Soeken K, GeigerBrown J, De Forge BR. Prevalence and correlates of depression among patients with head and neck cancer: a systematic review of implications for research. Oncol Nurs Forum. 2009;36(3):E107-25.

5. Deng YT, Zhong WN, Jiang Y. Measurement of distress and its alteration during treatment in patients with nasopharyngeal carcinoma. Head Neck. 2014;36(8):1077-86.

6. Lue BH, Huang TS, Chen HJ. Physical distress, emotional status, and quality of life in patients with nasopharyngeal cancer complicated by postradiotherapy endocrinopathy. Int J Radiat Oncol Biol Phys. 2008;70(1):28-34.

7. Johansson M, Rydén A, Finizia C. Mental adjustment to cancer and its relation to anxiety, depression, HRQL and survival in patients with laryngeal cancer - A longitudinal study. BMC Cancer. 2011;30(11):283-92.

8. Singer S, Krauss O, Keszte J, Siegl G, Papsdorf K, Severi $\mathrm{E}$, et al. Predictors of emotional distress in patients with head and neck cancer. Head Neck. 2012; 34(2):180-7. 9. Yang HC1, Wang LF, Chang JT, Fang F. [The healthrelated quality of life and bio-psycho-social adaptation effects in patients with head and neck cancer: a longitudinal study]. Hu Li Za Zhi. 2013;60(5):41-52.

10. Erickson JM, Kim SL, Jenna KJ, Davis MA. SelfCare Strategies to Relieve Fatigue in Patients Receiving Radiation Therapy. Clin J Oncol Nurs. 2013;17(3):19-24. 
11. Dropkin MJ. Anxiety, coping strategies, and coping behaviors in patients undergoing head and neck cancer surgery. Cancer Nurs. 2001;24(2):143-8.

12. López AL, Guerrero S. Perspectiva internacional del uso de la teoría general de Orem. Invest. Educ. Enferm. 2006;(24)2:90-100.

13. Santos $R$, Varez $P$, Abril $S$, Rocabert $L$, Ruiz M, Mañé B. Reflexiones acerca del uso y utilidad de los modelos y teorías de enfermería en la práctica asistencia. Enferm Clin. 2006;16(4):218-21.

14. Zigmond A, Snaith P. The Hospital Anxiety and Depression Scale. Acta Psychiatr Scand. 1983;67(6):361-70

15. Singer S, Danker H, Dietz A, Hornemann B, Koscielny $S$, Oeken J, et al. Screening for mental disorders in laryngeal cancer patients: a comparison of 6 methods. Psychooncology. 2008;17(3):280-6.

16. Quintana JM, Padierna A, Esteban C, Arostegui I, Bilbao A, Ruiz I. Evaluation of the psychometric characteristics of the Spanish version of the Hospital Anxiety and Depression Scale. Acta Psychiatr Scand. 2003;107(3):216-21.

17. Mahoney FI, Barthel DW. Functional evaluation: the BARTHEL index. Md State Med J. 1965;14:61-5.

18. Cid Ruzafa J, Damián Moreno J. Valoración de la discapacidad física: el índice de Barthel. Rev Esp Salud Pública. 1997;71:127-37.

19. Hospital Universitario Reina Sofía (ES). Dirección de Enfermería. Catálogo de planes de Cuidados de Enfermería: Manual [Internet]. Córdoba; 2015. [Acesso 1 out 2015]. Disponível em: http://www. juntadeandalucia.es/servicioandaluzdesalud/hrs3/ index.php?id=catalogo_planes_cuidados.

20. Tang Y, Luo D, Rong X, Shi X, Peng Y. Psychological Disorders, Cognitive Dysfunction and Quality of Life in Nasopharyngeal Carcinoma Patients with RadiationInduced Brain Injury. PLoS One. 2012;7(6):e36529.

21. Artal SR, Collado JI, Sebastián JM, Bondia A, Valles H. Valoración del grado de afectación sobre la salud psíquica en el paciente prelaringectomizado. Acta Otorrinolaringol Esp. 2011;62(3):220-7.

22. Neilson KA, Pollard AC, Boonzaier AM, Corry J, Castle

$D J$, Mead KR, et al. Psychological distress (depression and anxiety) in people with head and neck cancers. Med J Aust. 2010 Sep 6;193(5 Suppl):S48-51.
Received: Apr. 3 $3^{\text {rd }} 2015$

Accepted: Nov. 26 2015
Corresponding Author:

Clara Inés Flórez Almonacid

Universidad de Córdoba. Facultad de Medicina y Enfermería.

Departamento de Enfermería

Edificio Sur

14004, Córdoba, Andalucía, España

E-mail: en1flalc@uco.es
Copyright $\odot 2016$ Revista Latino-Americana de Enfermagem This is an Open Access article distributed under the terms of the Creative Commons (CC BY).

This license lets others distribute, remix, tweak, and build upon your work, even commercially, as long as they credit you for the original creation. This is the most accommodating of licenses offered. Recommended for maximum dissemination and use of licensed materials. 